CLINICAL STUDY

\title{
Serum high-mobility group box-1 levels are positively associated with micro- and macroalbuminuria but not with cardiovascular disease in type 1 diabetes: the EURODIAB Prospective Complications Study
}

\author{
Johanna W M Nin ${ }^{1,2,3}$, Isabel Ferreira ${ }^{1,2,3,4}$, Casper G Schalkwijk ${ }^{2,3}$, Martin H Prins ${ }^{1,4}$, Nish Chaturvedi ${ }^{5}$, \\ John H Fuller ${ }^{6}$, Coen D A Stehouwer ${ }^{2,3}$ and EURODIAB Prospective Complications Study Group ${ }^{\dagger}$ \\ ${ }^{1}$ Care and Public Health Research Institute (CAPHRI) and ${ }^{2}$ Cardiovascular Research Institute Maastricht (CARIM), University of Maastricht, Maastricht, \\ The Netherlands, ${ }^{3}$ Department of Internal Medicine, University Hospital Maastricht, Universiteitssingel 50, PO Box 616, 6200 MD Maastricht, The \\ Netherlands, ${ }^{4}$ Department of Clinical Epidemiology and Medical Technology Assessment, University Hospital Maastricht, Maastricht, The Netherlands, \\ ${ }^{5}$ Imperial College London, National Heart and Lung Institute, International Centre for Circulatory Health, London, UK and ${ }^{6}$ Department of Epidemiology \\ and Public Health, Royal Free and University College London Medical School, London, UK
}

(Correspondence should be addressed to J W M Nin at Department of Internal Medicine, University Hospital Maastricht; Email: j.nin@maastrichtuniversity.nl)

${ }^{\dagger}$ (Members of the EURODIAB PCS group details are given in an acknowledgement section)

\begin{abstract}
Context and objective: High-mobility group box-1 (HMGB1) is a pro-inflammatory cytokine that may contribute to the pathogenesis of micro- and macrovascular complications commonly observed in diabetes. We investigated whether HMGB1 is associated with: i) markers of low-grade inflammation (LGI) and endothelial dysfunction (ED) and pulse pressure (PP, a marker of arterial stiffness); ii) prevalent nephropathy, retinopathy and cardiovascular disease (CVD) in type 1 diabetes; and iii) the potential mediating roles of LGI, ED and PP therein.

Design and methods: This was a cross-sectional nested case-control study of 463 patients (226 women; mean age $40 \pm 10$ years) with type 1 diabetes from the EURODIAB Prospective Complications Study. We used linear and binary or multinomial logistic regression analyses adjusted for traditional risk factors. Results: Serum Ln-HMGB1 levels were positively associated with LGI and ED (standardised $\beta=0.07$ (95\% confidence interval (CI): 0.02-0.12) and $\beta=0.08$ (95\% CI: 0.02-0.14) respectively), but not with PP. Higher Ln-HMGB1 (per unit) was associated with greater odds of micro- and macroalbuminuria: odds ratio $(\mathrm{OR})=1.24(95 \% \mathrm{CI}: 0.90-1.71)$ and $\mathrm{OR}=1.61$ (95\% CI: $1.15-2.25)$ respectively, $P$ for trend $=0.004$. Further adjustments for LGI or ED did not attenuate these associations. No such associations were found between Ln-HMGB1 and estimated glomerular filtration rate (eGFR), retinopathy or CVD, however.

Conclusions: In type 1 diabetes, higher serum HMGB1 levels are associated with greater prevalence and severity of albuminuria, though not with eGFR, retinopathy and CVD. Prospective studies are needed to clarify the causal role of HMGB1, if any, in the pathogenesis of vascular complications in type 1 diabetes.
\end{abstract}

European Journal of Endocrinology 166 325-332

\section{Introduction}

The pathophysiological mechanisms that could link hyperglycaemia in the development of micro- and macrovascular complications in patients with diabetes mellitus (DM) are still unclear. One of the proposed mechanisms involves advanced glycation end products (AGEs) and the receptor for AGEs (RAGE) $(1,2,3,4)$. Besides AGEs, RAGE can also be activated by other ligands such as high-mobility group box-1 (HMGB1) (5).

HMGB1 is a multifunctional nuclear DNA-binding protein that facilitates gene transcription (6). Extracellular HMGB1 released from necrotic cells (7) as well as from immune cells upon inflammatory stimuli (8) functions as a pro-inflammatory cytokine, which elicits pro-inflammatory responses from macrophages (9) and endothelial cells (10). Extracellular HMGB1, however, can also initiate tissue repair (11) and promote angiogenesis in animal models (12). In addition, HMGB1 functions as a chemotactic agent for endothelial precursor cells (13) and smooth muscle cells (14). Extracellular effects of HMGB1 are mediated not only by its binding to RAGE, but also, at least in part, by its binding to the receptors of the toll-like receptor family (15). The mechanisms behind the balance between the detrimental and the beneficial actions of 
HMGB1, and whether these actions might be receptor specific, are still unclear.

Owing mainly to its pro-inflammatory function, it has been suggested that HMGB1 may be involved in the development of vascular disease (16). In this line, higher serum HMGB1 levels have been reported in individuals with coronary heart disease $(17,18)$ or heart failure (19) compared with those without these diseases. Inflammation is involved in the development of diabetic nephropathy (20), and in this line, a recent study showed that HMGB1 may play a role in the development of diabetic nephropathy in rats (21).

Whether HMGB1 levels are associated with the presence and severity of nephropathy, retinopathy and cardiovascular disease (CVD) in patients with type 1 diabetes, and the potential roles of low-grade inflammation (LGI), endothelial dysfunction (ED) and arterial stiffness therein have never been investigated, however. We have, therefore, addressed these issues in a large group of patients with type 1 diabetes in the EURODIAB Prospective Complications Study (PCS).

\section{Subjects and methods}

\section{Subjects and study design}

We used data from the EURODIAB PCS, which is a follow-up of the EURODIAB insulin-dependent DM complications study that has been described in detail elsewhere $(22,23,24)$. Briefly, baseline investigations were performed between 1989 and 1991 on 3250 patients with type 1 diabetes. All patients gave informed consent and the study was approved by the Local Ethics Committees. Of the 3250 included patients, 1880 $(57.8 \%)$ returned for follow-up examination on average 7-9 years after the baseline examinations. At follow-up, a cross-sectional nested case-control study of markers of LGI and ED, and their associations with complications was performed in a subset of patients $(n=543)$. Cases were selected as those with greatest vascular complication burden as possible $(n=348)$ and controls were selected as those who were completely free of any complications (i.e. with no evidence of CVD, albuminuria and retinopathy; $n=195)$. The present crosssectional nested case-control study $(2,25,26,27,28$, $29,30,31$ ) includes 463 of the subjects whose complete data on serum levels of HMGB1 and other covariates of interest were available.

\section{Biomarkers}

Serum HMGB1 levels were measured in duplicate with a commercially available ELISA kit (Shino-Test Corporation, Tokyo, Japan) and the intra- and inter-assay coefficients of variation (CV) were 2.7 and $7.6 \%$ respectively.
Soluble vascular cell adhesion molecule-1 (sVCAM-1) and soluble E-selectin (sE-selectin) were measured in duplicate by sandwich enzyme immunoassays (R\&D Systems, Oxon, UK). The intra- and inter-assay CV for sVCAM-1 were 4.0 and $9.1 \%$, respectively, and for sE-selectin were 2.1 and $3.1 \%$ respectively $(2,26)$.

Total transforming growth factor $\beta 1$ (TGF $\beta 1$ ) was measured by an ELISA development system (R\&D Systems) and the intra- and inter-assay CV were 5.0 and $7.0 \%$ respectively (27). Plasma levels of C-reactive protein (CRP) were measured by a highly sensitive in-house ELISA, and plasma levels of interleukin 6 (IL6) and tumour necrosis factor $\alpha$ (TNF $\alpha$ ) were measured using commercially available ELISA kits (R\&D Systems). The intra- and inter-assay CV for CRP, IL6 and TNF $\alpha$ were 3.9 and $8.7 \%, 4.5$ and $9.0 \%$, and 7.3 and $8.5 \%$ respectively $(2,26)$.

\section{Other risk factors}

Blood pressure was measured twice in a seated position using a random zero sphygmomanometer (Hawskley, Lancing, UK), and appropriate cuff size, after the patients had rested for $5 \mathrm{~min}$, and the mean of the two readings were used in the analyses (32). Mean arterial pressure (MAP) was calculated as (systolic blood pressure $+(2 \times$ diastolic blood pressure $)) / 3$. Pulse pressure (PP) was calculated by subtracting the diastolic from the systolic blood pressure and was used as a marker of arterial stiffness $(32,33)$. Smoking habits were ascertained by questionnaire and the subjects were categorised as 'non', 'moderate' and 'heavy smokers', according to their levels of pack years smoked (none, below or above the sex-specific median respectively) (2). Weight and height were measured with indoor clothing without shoes and body mass index (BMI) was calculated. Fasting cholesterol and triglyceride levels were measured by enzymatic colorimetric tests (34). HbAlc was measured by a latex-enhanced turbidimetric immunoassay (Roche Products). The reference range for this assay was $4.2-6.2 \%$.

\section{Main outcomes}

Albumin excretion rates were measured from duplicate 24-h urine collections and micro- and macroalbuminuria were defined as an albumin excretion rate between 20 and $200 \mu \mathrm{g} / \mathrm{min}$ and above $200 \mu \mathrm{g} / \mathrm{min}$ respectively (22). Glomerular filtration rate (GFR) was estimated by the Cockcroft-Gault formula (35) and with the short modified diet in renal disease equation (36). Retinopathy was assessed from retinal photographs according to the EURODIAB protocol. Accordingly, non-proliferative retinopathy was defined as the presence of one or more micro-aneurysms, haemorrhages and/or hard exudates. Proliferative retinopathy was defined as any new vessels, fibrous proliferations, pre-retinal haemorrhage, vitreous haemorrhage or photocoagulation scars (37). 
CVD was defined as a positive medical history of a cardiovascular event, including myocardial infarction, angina, coronary artery bypass graft and/or stroke, and/or ischaemic changes on a centrally Minnesotacoded electrocardiogram (38).

\section{Statistical analyses}

All analyses were performed using the Statistical Package for Social Sciences (SPSS) version 15.0 for Windows (SPSS, Inc., Chicago, IL, USA). Variables with a skewed distribution (i.e. HMGB1, triglycerides, CRP, IL6, TNF $\alpha$ and TGF $\beta 1$ ) were $\log _{\mathrm{e}}$ transformed before further analyses. Comparisons of characteristics between the subjects with and without vascular complications were made using Student's $t$-test or $\chi^{2}$ test, as appropriate. In these analyses, cases were all those subjects with any vascular complication $(n=289)$; controls were all those without any vascular complication $(n=174)$.

Plasma markers of LGI were converted into an overall LGI score by averaging the Z-scores of Ln-CRP, Ln-IL6, Ln-TNF $\alpha$ and Ln-TGF $\beta 1$; similarly, plasma markers of ED were converted into an overall ED score by averaging the Z-scores of sVCAM-1 and sE-selectin $(2,3,4,26)$.
The Z-score represents the distance between an individual's biomarker score from the population's total mean in units of the population's s.D., and is thus a common transformation that enables the combination of several markers originally expressed in different units. The two scores thus obtained represent a more robust measure of the individual's levels of LGI and ED and have the advantage of reducing the influence of the biological variability expected when LGI or ED is characterised based on the levels of each biomarker separately, since these were only measured once.

Linear regression analyses were used to examine the extent to which Ln-HMGB1 was associated with each of the biomarkers of LGI and ED, as well as their overall scores, and PP. We reported standardised regression coefficients $(95 \%$ confidence interval (CI)) to allow comparison of the strength of the associations. These analyses were adjusted first for age, sex, duration of DM, case-control status, and conventional risk factors such as HbA1c, BMI, total cholesterol, MAP and smoking; secondly, for the use of antihypertensive medication; and thirdly, for estimated GFR (eGFR) estimated by Cockcroft-Gault formula.

We used multinomial logistic regression analyses to examine the associations between Ln-HMGB1 and the

Table 1 Clinical characteristics of the study population. Data are mean (S.D.), median (inter-quartile range) or percentages as appropriate.

\begin{tabular}{|c|c|c|c|}
\hline & \multicolumn{3}{|c|}{ All $(n=463)$} \\
\hline & $\begin{array}{l}\text { Vascular complications } \\
(n=289)\end{array}$ & $\begin{array}{l}\text { No vascular } \\
\text { complications }(n=174)\end{array}$ & $P$ value \\
\hline Age (years) & $41.8(10.4)$ & $35.9(8.1)$ & $<0.001$ \\
\hline $\operatorname{Sex}(\mathrm{M} / \mathrm{F}, \%)$ & $55 / 45$ & $45 / 55$ & 0.056 \\
\hline BMI $\left(\mathrm{kg} / \mathrm{m}^{2}\right)$ & $24.9(3.5)$ & $23.8(2.6)$ & $<0.001$ \\
\hline $\mathrm{HbA} 1 \mathrm{c}(\%)$ & $9.0(1.5)$ & $7.8(1.3)$ & $<0.001$ \\
\hline Duration of diabetes (years) & $25.2(9.1)$ & $15.3(7.0)$ & $<0.001$ \\
\hline Total cholesterol $(\mathrm{mmol} / \mathrm{l})$ & $5.49(1.12)$ & $5.00(1.09)$ & $<0.001$ \\
\hline Triglycerides (mmol/l) & $1.14(0.85-1.58)$ & $0.86(0.67-1.10)$ & $<0.001$ \\
\hline Smoking (non/moderate/heavy; \%) & $38.8 / 27.3 / 33.9$ & $51.2 / 31.0 / 17.8$ & 0.001 \\
\hline Diastolic blood pressure (mmHg) & $75(12)$ & $73(11)$ & 0.060 \\
\hline Systolic blood pressure (mmHg) & $126(22)$ & $114(14)$ & $<0.001$ \\
\hline MAP $(\mathrm{mmHg})$ & $92(13)$ & $87(11)$ & $<0.001$ \\
\hline $\mathrm{PP}(\mathrm{mmHg})$ & $51(19)$ & $41(11)$ & $<0.001$ \\
\hline Antihypertensive medication (\%) & 45.3 & 6.3 & $<0.001$ \\
\hline $\mathrm{eGFR}_{\mathrm{GC}}\left(\mathrm{ml} / \mathrm{min}\right.$ per $\left.1.73 \mathrm{~m}^{2}\right)$ & $96.9(27.7)$ & $114.0(17.5)$ & $<0.001$ \\
\hline $\mathrm{eGFR}_{\mathrm{MDRD}}\left(\mathrm{ml} / \mathrm{min}\right.$ per $\left.1.73 \mathrm{~m}^{2}\right)$ & $86.6(25.4)$ & $101.5(16.0)$ & $<0.001$ \\
\hline Albuminuria (normo/micro/macro; \%) & $38.1 / 23.5 / 38.4$ & - & - \\
\hline Retinopathy (no/background/proliferative; \%) & $12.1 / 41.5 / 46.4$ & - & - \\
\hline CVD (\%) & 38.1 & - & - \\
\hline HMGB1 (ng/ml) & $1.26(0.78-2.57)$ & $1.45(0.89-2.75)$ & 0.406 \\
\hline $\mathrm{CRP}(\mathrm{mg} / \mathrm{l})$ & $1.29(0.46-2.75)$ & $0.71(0.35-1.88)$ & $<0.001$ \\
\hline IL6 (pg/ml) & $2.12(1.34-3.94)$ & $1.57(1.06-2.50)$ & $<0.001$ \\
\hline $\mathrm{TNF} \alpha(\mathrm{pg} / \mathrm{ml})$ & $3.18(2.39-4.47)$ & $2.22(1.68-2.85)$ & $<0.001$ \\
\hline TGF $\beta 1$ (ng/ml) & $5.55(3.70-8.90)$ & $5.25(3.28-8.03)$ & 0.132 \\
\hline Inflammation score & $0.17(0.62)$ & $-0.28(0.54)$ & $<0.001$ \\
\hline sE-selectin (ng/ml) & $36(17)$ & $31(11)$ & $<0.001$ \\
\hline sVCAM-1(ng/ml) & $437(149)$ & $380(104)$ & $<0.001$ \\
\hline ED score & $0.14(0.80)$ & $-0.24(0.49)$ & $<0.001$ \\
\hline
\end{tabular}

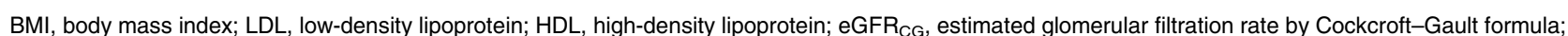
eGFR M $_{\text {MRD }}$ estimated glomerular filtration rate by short modification of diet in renal disease equation; CRP, C-reactive protein; IL6, interleukin 6; TNF $\alpha$, tumour necrosis factor $\alpha$; TGF $\beta 1$, transforming growth factor $\beta 1$; sE-selectin, soluble E-selectin; sVCAM-1, soluble vascular cell adhesion molecule-1; HMGB1, highmobility group box-1; MAP, mean arterial pressure; PP, pulse pressure; ED, endothelial dysfunction. 
presence and severity of albuminuria as well as retinopathy, and binary logistic regression analyses to investigate the associations between Ln-HMGB1 and prevalent CVD. These analyses were adjusted for the conventional CVD risk factors as listed above and use of antihypertensive medication and eGFR as described above, to ascertain independence from these factors. We further adjusted these associations for LGI and ED scores and PP to ascertain the extent to which these mechanisms could explain (i.e. mediate) a portion of the associations found, in which case the effect sizes (odds ratio (OR)) would be appreciably attenuated.

\section{Results}

Table 1 shows the characteristics of the patients with any vascular complications vs those without. Overall, individuals with vascular complications had a more adverse atherosclerotic risk profile as illustrated by more unfavourable levels of conventional risk factors, LGI, ED, $\mathrm{PP}$ and eGFR.

After adjustments for age, sex, HbAlc, duration of diabetes, case-control status, BMI, total cholesterol, MAP and smoking were made, serum Ln-HMGB1 levels were positively associated with LGI and ED scores (standardised regression coefficient $\beta=0.07$ (95\% CI: $0.02-0.12)$ and $\beta=0.08$ (95\% CI: $0.02-0.14)$ respectively), but not with PP (Table 2, model 1). Further adjustments made for antihypertensive medication and eGFR did not attenuate these positive associations (Table 2, models 2 and 3). Serum Ln-HMGB1 levels were not associated with eGFR, however.

After adjustments for conventional risk factors were made, Ln-HMGB1 levels were associated with greater odds for micro- and macroalbuminuria: $\mathrm{OR}=1.23$
(95\% CI: $0.90-1.70)$ and $\mathrm{OR}=1.61$ (95\% CI: $1.15-$ 2.26 ), respectively, $P$ for trend $=0.004$, per unit higher Ln-HMGB1 (Table 3, model 3; Fig. 1). When albuminuria was analysed as a continuous outcome, each unit increase in Ln-MHGB1 was associated with $3.9 \mu \mathrm{g} / \mathrm{min}$ (95\% CI: $0.3-7.9)$ in albuminuria $(P=0.030)$. No such associations were found between Ln-HMGB1 levels and prevalent CVD $(\mathrm{OR}=0.86(95 \% \mathrm{CI}$ : $0.66-1.12))$ or retinopathy $(\mathrm{OR}=0.94(95 \% \mathrm{CI}: 0.70-1.26)$ and $\mathrm{OR}=$ 0.90 (95\% CI: $0.64-1.26)$ for prevalent non-proliferative and proliferative retinopathy respectively), however.

Despite the positive associations between Ln-HMGB1 and circulating biomarkers of LGI as well as ED, the associations between HMGB1 and micro- and macroalbuminuria were not appreciably attenuated when these were further adjusted for the LGI score (model 4 vs model 3) or the ED score (model 5 vs model 3).

In additional analyses, we also examined whether the associations between HMGB1 with the presence and severity of nephropathy, retinopathy and CVD differed by the levels of patients' renal filtration, but found no significant effect-modification by eGFR, in any of our analyses (data not shown).

\section{Discussion}

The main finding of this study is that among individuals with type 1 diabetes, serum HMGB1 levels are positively associated with the presence and severity of albuminuria, though not with eGFR, retinopathy and CVD. In addition, HMGB1 levels were positively associated with markers of LGI and ED, but these did not explain the association of HMGB1 with albuminuria. This is the first study to investigate the associations between HMGB1

Table 2 Associations between serum levels of HMGB1 and markers of inflammation and ED, PP and eGFR $(n=463)$.

\begin{tabular}{|c|c|c|c|c|c|c|c|c|c|}
\hline \multirow{2}{*}{$\begin{array}{l}\text { Dependent } \\
\text { variable }\end{array}$} & \multicolumn{3}{|c|}{ Model 1} & \multicolumn{3}{|c|}{ Model 2} & \multicolumn{3}{|c|}{ Model 3} \\
\hline & $\beta$ & $95 \% \mathrm{Cl}$ & $P$ value & $\beta$ & $95 \% \mathrm{Cl}$ & $P$ value & $\beta$ & $95 \% \mathrm{Cl}$ & $P$ value \\
\hline $\mathrm{TNF} \alpha$ & 0.05 & $-0.04 ; 0.13$ & 0.270 & 0.05 & $-0.03 ; 0.13$ & 0.225 & 0.03 & $-0.04 ; 0.10$ & 0.409 \\
\hline TGF $\beta$ & 0.10 & $0.01 ; 0.19$ & 0.032 & 0.10 & $0.01 ; 0.19$ & 0.032 & 0.10 & $0.01 ; 0.19$ & 0.034 \\
\hline CRP & 0.07 & $-0.02 ; 0.15$ & 0.106 & 0.07 & $-0.02 ; 0.15$ & 0.106 & 0.07 & $-0.02 ; 0.15$ & 0.106 \\
\hline IL6 & 0.06 & $-0.03 ; 0.15$ & 0.210 & 0.06 & $-0.03 ; 0.15$ & 0.210 & 0.05 & $-0.04 ; 0.14$ & 0.255 \\
\hline Inflammation score & 0.07 & $0.02 ; 0.12$ & 0.011 & 0.07 & $0.02 ; 0.12$ & 0.010 & 0.06 & $0.01 ; 0.11$ & 0.016 \\
\hline sE-selectin & 0.09 & $0.00 ; 0.17$ & 0.053 & 0.09 & $0.00 ; 0.17$ & 0.051 & 0.09 & $0.00 ; 0.18$ & 0.047 \\
\hline sVCAM-1 & 0.09 & $-0.01 ; 0.17$ & 0.086 & 0.08 & $-0.01 ; 0.17$ & 0.068 & 0.07 & $-0.02 ; 0.15$ & 0.123 \\
\hline ED score & 0.08 & $0.02 ; 0.14$ & 0.010 & 0.08 & $0.02 ; 0.15$ & 0.007 & 0.08 & $0.02 ; 0.14$ & 0.012 \\
\hline PP & 0.02 & $-0.06 ; 0.09$ & 0.664 & 0.02 & $-0.06 ; 0.09$ & 0.652 & 0.02 & $-0.06 ; 0.09$ & 0.670 \\
\hline $\mathrm{eGFR}_{\mathrm{GC}}$ & -0.03 & $-0.11 ; 0.04$ & 0.377 & -0.04 & $-0.11 ; 0.03$ & 0.247 & - & - & - \\
\hline eGFR $\mathrm{MDRD}_{\mathrm{MDR}}$ & -0.03 & $-0.11 ; 0.05$ & 0.453 & -0.04 & $-0.12 ; 0.04$ & 0.310 & - & - & - \\
\hline
\end{tabular}

$\beta$, standardised regression coefficient: indicates change in dependent variable (in s.D.) per 1 s.D. increase in Ln-HMGB1; CI, confidence interval; TNF $\alpha$, tumour necrosis factor $\alpha$; TGF $\beta 1$, transforming growth factor $\beta 1$; CRP, C reactive protein; IL6, interleukin 6; sE-selectin, soluble E-selectin; sVCAM-1, soluble vascular

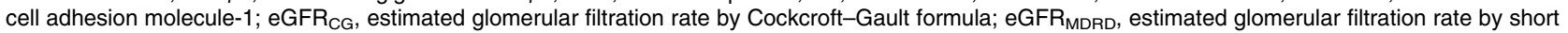
modification of diet in renal disease equation; PP, pulse pressure; MAP, mean arterial pressure; ED, endothelial dysfunction; HMGB1, high-mobility group box-1; BMI, body mass index. Model 1, adjusted for age, sex, HbA1c, duration of diabetes, case-control status, BMI, total cholesterol, triglycerides, smoking and MAP; model 2, model 1+ antihypertensive medication; model 3, model $2+$ eGFR by Cockcroft-Gault formula. 


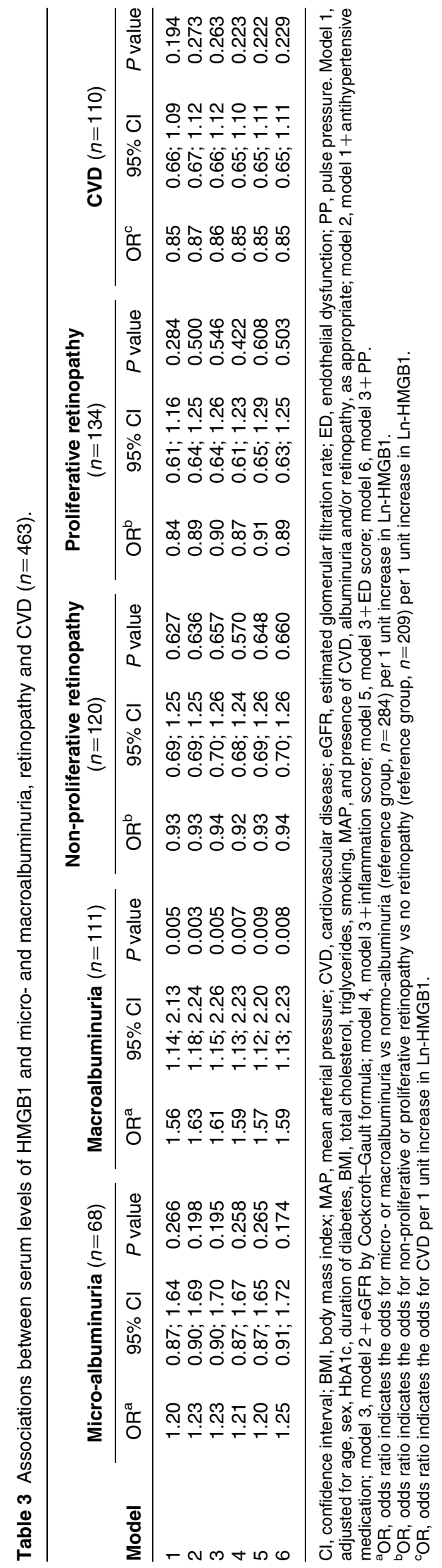

and micro- and macrovascular complications as well as markers of LGI and ED in patients with type 1 diabetes.

The positive association between HMGB1 and albuminuria observed in this study is supported by the findings in previous studies on rats, in which higher kidney HMGB1 levels were associated with the presence and severity of diabetic nephropathy (39). In addition, it has been reported that higher HMGB1 expression was found in the cytoplasm than in the nuclei of renal tissues in diabetic rats compared with mainly nucleic HMGB1 expression in renal tissues in control rats (21). The latter study has also reported higher RAGE expression and nuclear factor $\kappa \mathrm{B}(\mathrm{NF} \kappa \mathrm{B})$ activity, suggesting a pathogenic role of HMGB1 in the development of renal injury in diabetic rats through RAGE and activation of NFKB (21). However, we have measured serum HMGB1 only and it is unknown how serum levels relate to tissue levels. Extracellular HMGB1 may activate $\mathrm{NF} \kappa \mathrm{B}$ and initiate and amplify the upregulation of pro-inflammatory cytokines and adhesion molecules by binding to RAGE (5) or toll-like receptors $(15,16)$, and subsequently lead to increased risk for albuminuria.

Both HMGB1 (5) and AGEs (40) have been shown to be ligands of RAGE. Ligation of RAGE leads, via various intracellular signalling pathways, to the activation of transcription factor $\mathrm{NF} \kappa \mathrm{B}$, which may alter gene transcription and could lead to the upregulation of pro-inflammatory cytokines and adhesion molecules, processes that may play a role in the pathogenesis of vascular complications in type 1 diabetes. Both serum HMGB1 and sRAGE (2) levels were positively associated with the presence and severity of albuminuria in patients with type 1 diabetes. However, in this study, we could not find an association between serum HMGB1 levels and the presence of CVD, while in our previous studies we have shown that both SRAGE (3), as a reflection of RAGE, and AGEs (4), were positively associated with incident CVD. This suggests that although HMGB1, AGEs and (s)RAGE are interrelated, they may not contribute to the same pathways that underlie the pathogenesis of micro- and macrovascular complications. This may, at least in part, be explained by the various different receptors for both HMGB1 (15) and AGEs (41), and by the fact that beside HMGB1 and AGEs, many other ligands exist for RAGE (42).

The adverse association between higher levels of HMGB1 and the presence and severity of albuminuria was not appreciably explained by HMGB1-related LGI and/or ED, as estimated by the circulating biomarkers investigated herein. No association was found between HMGB1 and PP; therefore, this marker of arterial stiffness also could not explain any association between HMGB1 and albuminuria. These findings suggest that HMGB1, LGI, ED and PP may all constitute different and independent pathways leading to albuminuria in type 1 diabetes. Indeed, this is supported by the observations that both higher LGI and ED scores were independent of 


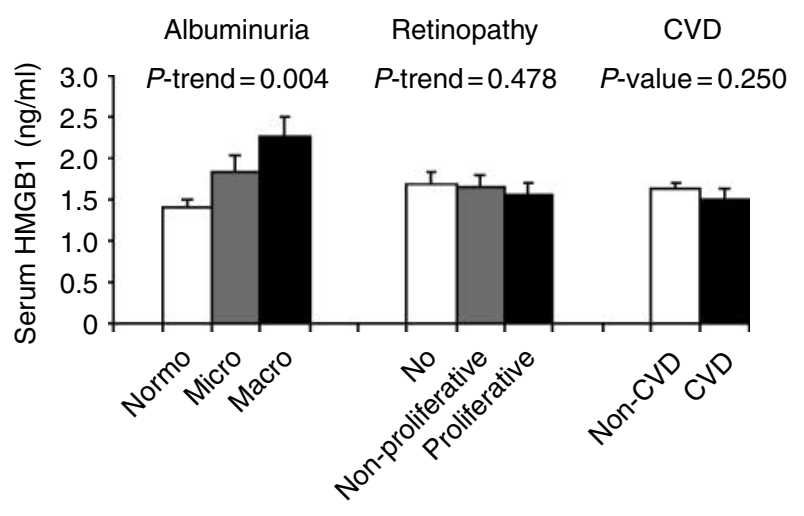

Figure 1 Serum high-mobility group box-1 levels according to the presence and severity of albuminuria and retinopathy and the presence of cardiovascular disease (CVD). Bars indicate geometric mean + S.E.M., which were adjusted for age, sex, HbA1c, duration of diabetes, case-control status, body mass index, total cholesterol, triglycerides, smoking, mean arterial pressure, antihypertensive medication, estimated glomerular filtration rate by Cockcroft-Gault formula, and presence of CVD, albuminuria and/or retinopathy, as appropriate.

serum HMGB1 levels associated with greater odds for micro- and macroalbuminuria: $\mathrm{OR}=1.51$ (95\% CI: $0.88-2.59$ ) and $\mathrm{OR}=1.86$ (95\% CI: $1.10-3.18)$ per unit higher LGI score, respectively, and $\mathrm{OR}=1.56(95 \%$ CI: 0.97-2.49) and OR $=2.08$ (95\% CI: 1.33-3.27) per unit higher ED score respectively. Although to a smaller extent, PP (per $10 \mathrm{mmHg}$ ) was also associated with greater odds for microalbuminuria $(\mathrm{OR}=1.09$ (95\% CI: $0.86-1.38))$ and macroalbuminuria $(\mathrm{OR}=1.20(95 \%$ CI: 0.97-1.49)), independent of HMGB1 levels.

The lack of an association between serum levels of HMGB1 and CVD observed in this study is in contrast to the positive associations that have been reported between serum levels of HMGB1 and coronary artery disease as well as heart failure in three previous studies, all of which were conducted in patients with type 2 diabetes $(17,18,19)$. In view of the strong associations observed between HMGB1 and LGI, ED as well as albuminuria, all of which are strong correlates of CVD, the lack of associations between HMGB1 and CVD as well as retinopathy is difficult to conciliate. We cannot discard the possibility that a type II error may have occurred and that we thus did not find an association between HMGB1 and prevalent CVD due to the play of chance. Further studies, preferably prospective, are needed to establish these associations more definitely. Indeed, the fact that we examined the associations in the context of a cross-sectional nested case-control study is also a limitation to our study, and any inferences about causality should thus be made with caution. Since there are no longitudinal data of this type in large groups of type 1 diabetes at this time, the present cross-sectional study may serve as a reasonable starting point to further explore these associations. In addition, we defined presence of CVD as a positive medical history of a cardiovascular event and, as such, may have missed subclinical cardiovascular complications. Use of statins, which could inhibit HMGB1 levels, was not accounted for in our study; these data were not retrieved given its rare prescription to patients with type 1 diabetes at the time this case-control study was done. Altogether, these limitations may have led to a dilution of the associations investigated herein. Finally, our findings were confined to individuals with type 1 diabetes and therefore may not be directly extrapolated to non-diabetic populations.

In conclusion, higher serum levels of HMGB1 are cross-sectionally associated with a higher prevalence of micro- and macroalbuminuria, but seemingly not with eGFR, retinopathy and CVD, in patients with type 1 diabetes. Further prospective studies are needed to further clarify the causal role of HMGB1, if any, in the pathophysiology of micro- and macrovascular complications in type 1 diabetes.

\section{Declaration of interest}

The authors declare that there is no conflict of interest that could be perceived as prejudicing the impartiality of the research reported.

\section{Funding}

The EURODIAB PCS was supported by grants from the Wellcome Trust, the European Community and Diabetes UK. Dr I Ferreira is supported by a research grant from the Dutch Heart Foundation (NHS; grant \#2006T050).

\section{Acknowledgements}

We thank all the investigators and patients who very kindly participated in the study. Members of the EURODIAB PCS group are B Karamanos, A Kofinis and K Petrou (Hippokration Hospital, Athens, Greece); F Giorgino, G Picca, A Angarano, G De Pergola, L Laviola and R Giorgino (Internal Medicine, Endocrinology and Metabolic Diseases, Department of Emergency and Organ Transplantation, University of Bari, Bari, Italy); C Ionescu-Tirgoviste, A Coszma and C Guja (Clinic of Diabetes, Nutrition and Metabolic Diseases, Bucharest, Romania); M Songini, A Casu, M Pedron, S Pintus and M Fossarello (Diabetes Unit, Ospedale San Michele, Cagliari, Italy); J B Ferriss, G Grealy and D O Keefe (Cork University Hospital, Cork, UK); M Toeller and C Arden (Diabetes Research Institute, Heinrich-Heine University, Dusseldorf, Germany); R Rottiers, C Tuyttens and H Priem (University Hospital of Gent, Gent, Belgium); P Ebeling, M Kylliäinen and V A Koivisto (University Hospital of Helsinki, Helsinki, Finland); B Idzior-Walus, J Sieradzki, K Cyganek and B Solnica (Department of Metabolic Diseases, Jagiellonian University, Krakow, Poland); H H P J Lemkes and J C Lemkes-Stuffken (Leiden University Medical Centre, Leiden, The Netherlands); J Nunes-Correa, M C Rogado, L Gardete-Correia, M C Cardoso, A Silva, J Boavida and M Machado Sa Marques (Portuguese Diabetic Association, Lisbon, Portugal); G Michel, $\mathrm{R}$ Wirion and S Cardillo (Centre Hospitalier, Luxembourg, Luxembourg); G Pozza, R Mangili and V Asnaghi (Ospedale San Raffaele, Milan, Italy); E Standl, B Schaffler, H Brand and A Harms (City Hospital Schwabing, Munich, Germany); D Ben Soussan, O VerierMine, P Fallas and M C Fallas (Centre Hospitalierde Valenciennes, Valenciennes, France); J H Fuller, J Holloway, L Asbury and D J Betteridge (University College London, London, UK); G Cathelineau, A Bouallouche and B Villatte Cathelineau (Hospital Saint-Louis, Paris, France); F Santeusanio, G Rosi, V D’Alessandro, C Cagini, P Bottini and G P Reboldi (Diaprtimento di Medicina Interna, Perugia, Italy); R 
Navalesi, G Penno, S Bandinelli, R Miccoli and M Nannipieri (Dipartimento di Endocrinologia e Metabolismo, Pisa, Italy); G Ghirlanda, C Saponara, P Cotroneo, A Manto and A Minnella (Universita Cattolica del Sacro Cuore, Rome, Italy); J D Ward, S Tesfaye, S Eaton and C Mody (Royal Hallamshire Hospital, Sheffield, UK); M Borra, P Cavallo Perin, S Giunti, G Grassi, G F Pagano, M Porta, R Sivieri, F Vitelli and M Veglio (Dipartimento di Medicina Interna, Universitá di Torino and ASO CTO/CRF/Maria Adelaide, Turin, Italy); N Papazoglou and G Manes (General Hospital Papageorgiou of Thessaloniki, Greece); M Muggeo and M Iagulli (Vittorio Cacciatori, $\mathrm{V}$ Cattedra di Malattie del Metabolismo, Verona, Italy); K Irsigler and H Abrahamian (Hospital Vienna Lainz, Austria); S Walford, J Sinclair, S Hughes, V McLelland and J Ward (New Cross Hospital, Wolverhampton, UK) and G Roglic, Z Metelko and Z R Pepeonik (Vuk Vrhovac Institute for Diabetes, Zagreb, Croatia). Steering committee members were J H Fuller (London, UK); B Karamanos, Chairman (Athens, Greece); A-K Sjolie (Aarhus, The Netherlands); N Chaturvedi (London, UK); M Toeller (Dusseldorf, Germany); G Pozza, Cochairman (Milan, Italy); B Ferriss (Cork, UK); M Porta (Turin, Italy); R Rottiers (Gent, Belgium) and G Michel (Luxembourg). Coordinating centre members were J H Fuller, N Chaturvedi, J Holloway, D Webb and L Asbury (University College London, London, UK). Central laboratories members were G C Viberti, R Swaminathan, P Lumb, A Collins and S Sankaralingham (Guy's and St. Thomas Hospital, London, UK). Retinopathy Grading Centre members were S Aldington, T Mortemore and H Lipinski (Royal Postgraduate Medical School of Imperial College London, London, UK).

\section{References}

1 Brownlee M. Biochemistry and molecular cell biology of diabetic complications. Nature $2001 \quad \mathbf{4 1 4}$ 813-820. (doi:10.1038/ 414813a)

2 Nin JW, Ferreira I, Schalkwijk CG, Prins MH, Chaturvedi N, Fuller JH \& Stehouwer CD. Levels of soluble receptor for AGE are cross-sectionally associated with cardiovascular disease in type 1 diabetes, and this association is partially mediated by endothelial and renal dysfunction and by low-grade inflammation: the EURODIAB Prospective Complications Study. Diabetologia 2009 52 705-714. (doi:10.1007/s00125-009-1263-5)

3 Nin JW, Jorsal A, Ferreira I, Schalkwijk CG, Prins MH, Parving HH, Tarnow L, Rossing P \& Stehouwer CD. Higher plasma soluble receptor for advanced glycation end products (sRAGE) levels are associated with incident cardiovascular disease and all-cause mortality in type 1 diabetes: a 12-year follow-up study. Diabetes 201059 2027-2032. (doi:10.2337/db09-1509)

4 Nin JW, Jorsal A, Ferreira I, Schalkwijk CG, Prins MH, Parving HH, Tarnow L, Rossing P \& Stehouwer CD. Higher plasma levels of advanced glycation end products are associated with incident cardiovascular disease and all-cause mortality in type 1 diabetes: a 12-year follow-up study. Diabetes Care 201134 442-447. (doi:10. 2337/dc10-1087)

5 Hori O, Brett J, Slattery T, Cao R, Zhang J, Chen JX, Nagashima M, Lundh ER, Vijay S, Nitecki D, Morser J, Stern D \& Schmidt AM. The receptor for advanced glycation end products (RAGE) is a cellular binding site for amphoterin. Mediation of neurite outgrowth and co-expression of rage and amphoterin in the developing nervous system. Journal of Biological Chemistry 1995 270 25752-25761. (doi:10.1074/jbc.270.43.25752)

6 Bianchi ME \& Agresti A. HMG proteins: dynamic players in gene regulation and differentiation. Current Opinion in Genetics and Development 200515 496-506. (doi:10.1016/j.gde.2005.08. 007)

7 Scaffidi P, Misteli T \& Bianchi ME. Release of chromatin protein HMGB1 by necrotic cells triggers inflammation. Nature $2002 \mathbf{4 1 8}$ 191-195. (doi:10.1038/nature00858)

8 Rendon-Mitchell B, Ochani M, Li J, Han J, Wang H, Yang H, Susarla S, Czura C, Mitchell RA, Chen G, Sama AE, Tracey KJ \&
Wang H. IFN-gamma induces high mobility group box 1 protein release partly through a TNF-dependent mechanism. Journal of Immunology 2003 170 3890-3897.

9 Li J, Kokkola R, Tabibzadeh S, Yang R, Ochani M, Qiang X, Harris HE, Czura CJ, Wang H, Ulloa L, Wang H, Warren HS, Moldawer LL, Fink MP, Andersson U, Tracey KJ \& Yang H. Structural basis for the proinflammatory cytokine activity of high mobility group box 1. Molecular Medicine 20039 37-45.

10 Fiuza C, Bustin M, Talwar S, Tropea M, Gerstenberger E, Shelhamer JH \& Suffredini AF. Inflammation-promoting activity of HMGB1 on human microvascular endothelial cells. Blood 2003 101 2652-2660. (doi:10.1182/blood-2002-05-1300)

11 Straino S, Di Carlo A, Mangoni A, De Mori R, Guerra L, Maurelli R, Panacchia L, Di Giacomo F, Palumbo R, Di Campli C, Uccioli L, Biglioli P, Bianchi ME, Capogrossi MC \& Germani A. High-mobility group box 1 protein in human and murine skin: involvement in wound healing. Journal of Investigative Dermatology $2008 \mathbf{1 2 8}$ 1545-1553. (doi:10.1038/sj.jid.5701212)

12 Biscetti F, Straface G, De Cristofaro R, Lancellotti S, Rizzo P, Arena V, Stigliano E, Pecorini G, Egashira K, De Angelis G, Ghirlanda G \& Flex A. High-mobility group box-1 protein promotes angiogenesis after peripheral ischemia in diabetic mice through a VEGF-dependent mechanism. Diabetes $2010 \quad \mathbf{5 9}$ 1496-1505. (doi:10.2337/db09-1507)

13 Chavakis E, Hain A, Vinci M, Carmona G, Bianchi ME, Vajkoczy P, Zeiher AM, Chavakis T \& Dimmeler S. High-mobility group box 1 activates integrin-dependent homing of endothelial progenitor cells. Circulation Research 2007100 204-212. (doi:10.1161/01. RES.0000257774.55970.f4)

14 De Mori R, Straino S, Di Carlo A, Mangoni A, Pompilio G, Palumbo R, Bianchi ME, Capogrossi MC \& Germani A. Multiple effects of high mobility group box protein 1 in skeletal muscle regeneration. Arteriosclerosis, Thrombosis, and Vascular Biology 200727 2377-2383. (doi:10.1161/ATVBAHA.107.153429)

15 van Zoelen MA, Yang H, Florquin S, Meijers JC, Akira S, Arnold B, Nawroth PP, Bierhaus A, Tracey KJ \& van der Poll T. Role of tolllike receptors 2 and 4, and the receptor for advanced glycation end products (Rage) in Hmgb1 induced inflammation in vivo. Shock 200931 280-284. (doi:10.1097/SHK.0b013e318186262d)

$16 \mathrm{Li} \mathrm{W,} \mathrm{Sama} \mathrm{AE} \mathrm{\&} \mathrm{Wang} \mathrm{H.} \mathrm{Role} \mathrm{of} \mathrm{HMGB1} \mathrm{in} \mathrm{cardiovascular}$ diseases. Current Opinion in Pharmacology 2006 6 130-135. (doi:10.1016/j.coph.2005.10.010)

17 Hu X, Jiang H, Bai Q, Zhou X, Xu C, Lu Z, Cui B \& Wen H. Increased serum HMGB1 is related to the severity of coronary artery stenosis. Clinica Chimica Acta 2009406 139-142. (doi:10.1016/ j.cca.2009.06.016)

18 Yan XX, Lu L, Peng WH, Wang LJ, Zhang Q, Zhang RY, Chen QJ \& Shen WF. Increased serum HMGB1 level is associated with coronary artery disease in nondiabetic and type 2 diabetic patients. Atherosclerosis 2009205 544-548. (doi:10.1016/j. atherosclerosis.2008.12.016)

19 Wang LJ, Lu L, Zhang FR, Chen QJ, De Catherina R \& Shen WF. Increased serum high-mobility group box-1 and cleaved receptor for advanced glycation endproducts levels and decreased endogenous secretory receptor for advanced glycation endproducts levels in diabetic and non-diabetic patients with heart failure. European Journal of Heart Failure 201113 440-449. (doi:10.1093/eurjhf/ hfq231)

20 Rivero A, Mora C, Muros M, Garcia J, Herrera H \& NavarroGonzalez JF. Pathogenic perspectives for the role of inflammation in diabetic nephropathy. Clinical Science 2009116 479-492. (doi:10.1042/CS20080394)

21 Kim J, Sohn E, Kim CS, Jo K \& Kim JS. The role of high-mobility group box-1 protein in the development of diabetic nephropathy. American Journal of Nephrology 201133 524-529. (doi:10.1159/ 000327992 )

22 Chaturvedi N, Bandinelli S, Mangili R, Penno G, Rottiers RE \& Fuller JH. Microalbuminuria in type 1 diabetes: rates, risk factors and glycemic threshold. Kidney International $200160219-227$. (doi:10.1046/j.1523-1755.2001.00789.x) 
23 Chaturvedi N, Sjoelie AK, Porta M, Aldington SJ, Fuller JH, Songini M \& Kohner EM. Markers of insulin resistance are strong risk factors for retinopathy incidence in type 1 diabetes. Diabetes Care 200124 284-289. (doi:10.2337/diacare.24.2.284)

24 Group TEICS. Microvascular and acute complications in IDDM patients: the EURODIAB IDDM Complications Study. Diabetologia 199437 278-285. (doi:10.1007/BF00398055)

25 Schram MT, Chaturvedi N, Schalkwijk C, Giorgino F, Ebeling P, Fuller JH \& Stehouwer CD. Vascular risk factors and markers of endothelial function as determinants of inflammatory markers in type 1 diabetes: the EURODIAB Prospective Complications Study. Diabetes Care 200326 2165-2173. (doi:10.2337/diacare.26.7. 2165)

26 Schram MT, Chaturvedi N, Schalkwijk CG, Fuller JH \& Stehouwer CD. Markers of inflammation are cross-sectionally associated with microvascular complications and cardiovascular disease in type 1 diabetes - the EURODIAB Prospective Complications Study. Diabetologia 200548 370-378. (doi:10. 1007/s00125-004-1628-8)

27 Chaturvedi N, Schalkwijk CG, Abrahamian H, Fuller JH \& Stehouwer CD. Circulating and urinary transforming growth factor beta1, Amadori albumin, and complications of type 1 diabetes: the EURODIAB Prospective Complications Study. Diabetes Care 200225 2320-2327. (doi:10.2337/diacare.25.12.2320)

28 Gruden G, Bruno G, Chaturvedi N, Burt D, Schalkwijk C, Pinach S, Stehouwer CD, Witte DR, Fuller JH \& Perin PC. Serum heat shock protein 27 and diabetes complications in the EURODIAB Prospective Complications Study: a novel circulating marker for diabetic neuropathy. Diabetes 200857 1966-1970. (doi:10. 2337/db08-0009)

29 Schalkwijk CG, Chaturvedi N, Schram MT, Fuller JH \& Stehouwer CD. Adiponectin is inversely associated with renal function in type 1 diabetic patients. Journal of Clinical Endocrinology and Metabolism 200691 129-135. (doi:10.1210/jc.2005-1117)

30 Schram MT, Schalkwijk CG, Bootsma AH, Fuller JH, Chaturvedi N \& Stehouwer $\mathrm{CD}$. Advanced glycation end products are associated with pulse pressure in type 1 diabetes: the EURODIAB Prospective Complications Study. Hypertension 200546 232-237. (doi:10. 1161/01.HYP.0000164574.60279.ba)

31 Soedamah-Muthu SS, Chaturvedi N, Teerlink T, Idzior-Walus B, Fuller JH \& Stehouwer CD. Plasma homocysteine and microvascular and macrovascular complications in type 1 diabetes: a cross-sectional nested case-control study. Journal of Internal Medicine 2005258 450-459. (doi:10.1111/j.1365-2796.2005. 01560.x)

32 Schram MT, Chaturvedi N, Fuller JH \& Stehouwer CD. Pulse pressure is associated with age and cardiovascular disease in type 1 diabetes: the Eurodiab Prospective Complications Study. Journal of Hypertension 200321 2035-2044. (doi:10.1097/ 00004872-200311000-00012)
33 Stehouwer CD, Henry RM \& Ferreira I. Arterial stiffness in diabetes and the metabolic syndrome: a pathway to cardiovascular disease. Diabetologia 200851 527-539. (doi:10.1007/s00125-0070918-3)

34 Fossati P \& Prencipe L. Serum triglycerides determined colorimetrically with an enzyme that produces hydrogen peroxide. Clinical Chemistry 198228 2077-2080.

35 Cockcroft DW \& Gault MH. Prediction of creatinine clearance from serum creatinine. Nephron 197616 31-41. (doi:10.1159/ 000180580)

36 Levey AS, Bosch JP, Lewis JB, Greene T, Rogers N \& Roth D. A more accurate method to estimate glomerular filtration rate from serum creatinine: a new prediction equation. Modification of Diet in Renal Disease Study Group. Annals of Internal Medicine 1999130 $461-470$.

37 Aldington SJ, Kohner EM, Meuer S, Klein R \& Sjolie AK. Methodology for retinal photography and assessment of diabetic retinopathy: the EURODIAB IDDM Complications Study. Diabetologia 199538 437-444. (doi:10.1007/BF00410281)

38 Koivisto VA, Stevens LK, Mattock M, Ebeling P, Muggeo M, Stephenson J \& Idzior-Walus B. Cardiovascular disease and its risk factors in IDDM in Europe. EURODIAB IDDM Complications Study Group. Diabetes Care 199619 689-697. (doi:10.2337/diacare. 19.7.689)

39 Li F, Yang N, Zhang L, Tan H, Huang B, Liang Y, Chen M \& Yu X. Increased expression of toll-like receptor 2 in rat diabetic nephropathy. American Journal of Nephrology 201032 179-186. (doi:10.1159/000317023)

40 Kislinger T, Fu C, Huber B, Qu W, Taguchi A, Du Yan S, Hofmann M, Yan SF, Pischetsrieder M, Stern D \& Schmidt AM. $N(\varepsilon)$-(carboxymethyl)lysine adducts of proteins are ligands for receptor for advanced glycation end products that activate cell signaling pathways and modulate gene expression. Journal of Biological Chemistry 1999274 31740-31749. (doi:10.1074/jbc. 274.44.31740)

41 Ohgami N, Nagai R, Ikemoto M, Arai H, Kuniyasu A, Horiuchi S \& Nakayama H. Cd36, a member of the class b scavenger receptor family, as a receptor for advanced glycation end products. Journal of Biological Chemistry 2001276 3195-3202. (doi:10. 1074/jbc.M006545200)

42 Hofmann MA, Drury S, Fu C, Qu W, Taguchi A, Lu Y, Avila C, Kambham N, Bierhaus A, Nawroth P, Neurath MF, Slattery T, Beach D, McClary J, Nagashima M, Morser J, Stern D \& Schmidt AM. RAGE mediates a novel proinflammatory axis: a central cell surface receptor for S100/calgranulin polypeptides. Cell 199997 889-901. (doi:10.1016/S0092-8674(00)80801-6)

Received 28 July 2011

Revised version received 19 October 2011

Accepted 28 November 2011 